\title{
Model Minority Stereotype and Racialized Habitus: Chinese Canadian Youth Struggling with Racial Discrimination at School
}

\author{
Dan Cui
}

Dan Cui is an assistant professor in the Department of Child and Youth Studies at Brock University. Her research interests include sociology of education; sociology of children and youth; immigration, integration, and transnationalism; intersectionality of race, class, and gender; social justice and equity studies; and qualitative research methods. Email: dcui@brocku.ca

This paper examines how Chinese Canadian youth struggle with the model minority stereotype and experience racial discrimination at school. Three negative connotations associated with model minority stereotype are identified, which respectively treat Chinse students as academic achievers and thus social nerds, undesirable immigrants (descendants) from the non-Western world, and targets of bullying. Drawing on Bourdieu, I elaborate on a concept of racialized habitus, particularly in relation to the model minority stereotype. I argue that in addition to the existing theorization of racism as institutional and systemic, racism has also been level as a racialized habitus.

Key words: model minority; racialized habitus; Chinese Canadian youth; racism; Bourdieu maintained and reproduced at the individual

In the age of globalization and transnational migration, Chinese immigrants are one of the largest immigrant groups in Canada (Statistics Canada, 2011). However, research with Chinese immigrant youth, particularly the second generation, has not been fully developed in the Canadian context. This deficit is partly due to the "model minority" discourse, which depicts Chinese students as academic achievers (Peterson, 1966a), leading their struggles as members of a racialized minority group to be less visible to academics. The few existing studies on this population have primarily concentrated on comparing and explaining their educational aspirations and occupational achievements in terms of ethnic variations and intergenerational mobility (Boyd, 2008; Reitz, Zhang, \& Hawkins, 2011). However, racialized minority youth may still regard themselves as outsiders even if they are educationally successful and economically included. The Canadian Ethnic Diversity Survey revealed that 33\% of children of Chinese immigrants reported experiencing racial discrimination, and this figure ranks second highest after African Canadians (Reitz \& Banerjee, 2007). In this context, this paper aims to explore how Chinese Canadian youth struggle with the model minority stereotype and experience racial discrimination in Canadian society. Drawing on sociologist Pierre Bourdieu (1990), I argue that the model minority discourse, which was deeply embedded in the historical field, has continuously and discursively maintained and reproduced a racist social order in contemporary fields, such as school and media. It continues to frame "the rules of the game" in terms of whose capital is valued, who is allowed to enter the field as legitimate members, and who can occupy the dominant position in that field. In particular, the model minority stereotype plays a significant role in framing people's ways of thinking about, and acting toward, Chinese Canadian youth. In other words, it contributes to the development of a specific kind of racialized habitus toward Chinese immigrants and their descendants. In this sense, the model minority stereotype and social agents' racialized habitus, particularly in relation to Chinese Canadian youth, are inextricably intertwined and mutually constructed. Theoretically, I argue that racism is not only systemic and institutional, but also individual. It functions as a racialized habitus, an embodied and internalized racist social structure conditioned by both the past and the present fields. It is a product and manifestation of both collective and individual racist history. This paper makes a theoretical and empirical contribution to Bourdieu's concept of habitus, which has been overwhelmingly 
employed to study social class, by highlighting how habitus is also racialized and group specific.

The paper has three parts. First, I will review the history and literature of the model minority stereotype. Second, I will introduce Bourdieu's theory of practice, particularly the concept of habitus, and some existing studies using a Bourdieusian perspective to study habitus and race, followed by a brief description of research methods and participants in this study. Finally, I will discuss three problematic connotations associated with the model minority stereotype, including foreign competitors and antisocial nerds, undesirable immigrants, and weak and obedient targets of bullying, all of which are evidenced in a recent example from Canadian media ("Too Asian?", Findlay \& Köhler, 2010) and in my own interview data with Chinese students. I will further explore how these biased assumptions, underpinned by the model minority stereotype, manifest and in turn contribute to the development of social agents' racialized habitus.

\section{"Model minority" stereotype}

The label of "model minority" applied to Asians in North America was coined by sociologist William Peterson in two articles he wrote in 1966. One was "Success Story: Japanese American Style," published in January in The New York Times and the other was "Success Story of One Minority in the US" in U.S. News and World Report in December, which focused on Chinese Americans. As Peterson (1966b) stated in the second article:

At a time when Americans are awash in worry over the plight of racial minorities, one such minority, the nation's 300,000 Chinese Americans, is winning wealth and respect by dint of its own hard work ... being taught in Chinatown is the old idea that people should depend on their own efforts-not a welfare check in order to reach America's Promised Land ... At a time when it is being proposed that hundreds of billions be spent to uplift Negroes and other minorities, the nation's 300,000 Chinese Americans are moving ahead on their own with no help from anyone. (p. 73)

After centuries of suffering from racial discrimination and media denigration as "yellow peril," this sudden honour and adulation from mainstream society indeed surprised the Chinese community. However, some sober scholars immediately dismissed it as simply a media invention out of nowhere, which did not reflect the real conditions of Chinese Americans in the 1960s (Wang, 2008). As Lihshing Wang argues, all Asian American groups continued to suffer from institutional discrimination, social isolation, and political disenfranchisement. By highlighting the constructed Asian American's success while erasing their suffering, the media aimed to reinforce the ideology that America is "a land of unlimited opportunity" for immigrants only if they remain self-sufficient, hardworking, and docile. Moreover, given that the model minority discourse emerged during the civil rights movement of the 1960s, scholars denounced it as a political and ideological construction designed to discredit the ongoing African American struggle for racial equality and economic justice (J. Lee, 1998; Suzuki, 2002). Because it demarcated a racial line between Asian Americans and whites on the one hand and other minorities on the other, the model minority discourse was criticized for creating "a calculated contrast between the quiet, law-abiding, motivated, and diligent Asian American families and the rowdy, lazy, defiant, broken, and welfare-dependent families of other races" (Wang, 2008, p. 24). As Robert G. Lee (1999) cogently points out, "the elevation of Asian Americans to the position of model minority had less to do with the actual success of Asian Americans than to the perceived failure-or worse, refusal-of African Americans to assimilate" (p. 145). What remains hidden behind the model minority discourse is the assumption that racism and social injustice are not serious issues-"since Asians can make it, why not you?" (Yu, 2006). Literature reviews in education and other disciplines similarly point out how the model minority stereotype divides social groups who may otherwise collaborate for social change (Chang, 2017; Poon et al., 2016). 
Since the 1960s, the model minority stereotype has replaced the old "yellow peril" stereotype for Asians in North America. Despite the seemingly positive discourse change, it has a range of detrimental consequences that further disadvantage Asians in many areas. For example, being viewed as educationally and economically successful, Asian Americans were excluded from federal affirmative action regulations as a minority group (Suzuki, 2002). Asian students may not be eligible for university minority scholarships (Takagi, 1992) and some funding agencies do not include Asians in their definition of underrepresented racial minorities, which results in inadequate funded research about this population (Museus \& Kiang, 2009). Although labelled as "model," their "minority" status in relation to the dominant white group remains unchanged. In reality, Asian Americans encounter many systemic and institutional barriers similar to their Black, Latino, and Native American peers (Chou \& Feagin, 2008; Museus, 2009).

Despite this fact, however, some people tend to deny the suffering and needs of Asian Americans by citing oversimplified statistics about their higher educational and occupational attainment and income compared with other groups (Museus \& Kiang, 2009). In fact, when the socioeconomic data on Asian Americans were disaggregated, the annual per capita income of this population was dramatically less than their white counterparts with the same level of education (Yu, 2006). In a similar vein, when enrollment data were disaggregated by institutional type, researchers found that community colleges (e.g., 2-year) enrolled the largest concentration of Asian students of all types of higher education (e.g., 4-year university), clashing with the biased assumption that Asian students are taking over Ivy League institutions (Assalone \& Fann, 2017).

Like all other racialized minorities, Asians in North America continue to suffer from racial discrimination, hate crimes, unequal opportunity and participation in mainstream society, and institutional barriers in accessing professional jobs and promotions (Guo, 2013; Wing, 2007; Yu, 2006). Moreover, the model minority discourse constructs Asians as nerdy and lacking social skills, which makes them more likely to be rejected by peers (Zhang, 2010). It has been argued that frequently rejected children often suffer from stress, loneliness, depression, and damaging and risky behaviours (Sunwolf \& Leets, 2004, as cited by Zhang, 2010). Further, empirical studies show that people's perceptions of and interactions with Asians are consistent with media stereotypes; therefore, the model minority discourse presented by the media has subjected Chinese American adolescents to both verbal and physical peer harassment (Qin, Way, \& Mukherjee, 2008). Despite the harmful effects, people tend to trivialize the "smart Asian" stereotypes as "just joking" (Raby, 2004). Therefore, more research is needed to better understand how the model minority stereotype affects the school experiences of Chinese youth, especially in the Canadian context because less Canadian research on this topic is available compared to the United States (with a few exceptions, such as Cui, 2015, 2017; G. Li, 2003).

Significantly, in November 2010, the popular Canadian newsmagazine Maclean's published a provocative article, "Too Asian?" which blamed Canadian universities, such as the University of Toronto and UBC, for accepting too many Asian students. These students were depicted as only academically focused, and their competitiveness was seen to deprive white students of postsecondary educational opportunities. The article also criticized Asian students for being antisocial, with their very presence on Canadian campuses not only ruining the traditional university life, which is characterized by parties, sports, and alcohol, but also creating ethnic enclaves and segregation. The publication of the "Too Asian?" article demonstrates a contemporary example of model minority discourse contextualized in Canada. Some key arguments of the "Too Asian?" article aligned very well with my interview data with Chinese Canadian youth. So, drawing on Bourdieu, I will explore how the model minority stereotype reflects and at the same time maintains and reproduces the racist order of historical and present fields as well as social agents' racialized habitus. 


\section{A Bourdieusian perspective}

Bourdieu's theory of practice provides an important theoretical framework for this study. Specifically, Bourdieu views social agents' practice as an interplay between three components: field, capital, and habitus. A field is a structured social space that contains people who dominate and people who are dominated (Bourdieu, 1998). Social agents are hierarchically positioned within the field depending on the interaction of capital at their disposal, the habitus in which they are inculcated, and the rules of the field. Bourdieu (1986) conceptualizes three types of capital: cultural capital (e.g., tastes and styles), social capital (e.g., network), and economic capital (e.g., money). Whether social agents are allowed to enter a field, and what positions they may occupy in that field, is not simply determined by the volume and types of capital they have, but also depends on the specific rules of the field and the strategies they use to activate their capital (Bourdieu, 1990; Bourdieu \& Wacquant, 1992; Thomson, 2008). When social agents' capital is valued by a specific field, they are in dominant positions, thus have the symbolic power to legitimate their actions and influence the rules of the field. More importantly, social agents develop systems of durable dispositions (i.e., habitus), which are structured by their experiences and the circumstances of the fields (Bourdieu, 1977). Social agents' habitus is not fixed but evolving, which in turn structures their present and future practices (Marton, 2008). Bourdieu (1994) theorized habitus as "structured and structuring structure" (p. 170). Habitus is a structure in the sense that it is not random but systemically ordered, comprising a system of durable dispositions that generate perceptions, appreciations, and practices. The concepts of field, capital, and habitus provide important theoretical insights for understanding social agents' racist ways of thinking and doing.

The existing studies from a Bourdieusian perspective tend to overwhelmingly focus on analyzing social class (Ball, Davies, David, \& Reay, 2002; Lareau, Evans, \& Yee, 2016; Lehmann, 2012). As Diane Reay (2004) argues, it is possible to use Bourdieu's theoretical framework to develop an understanding of habitus as shaped by gender and race, yet, there are very limited studies that use the Bourdieusian perspective to study race. Among the few conceptions, Derron Wallace (2017) breaks down the links between cultural capital and whiteness by examining Black cultural capital among middle-class Black Caribbean youth in South London. And Megan Watkins and Greg Noble (2013) challenge the Western educational perspective that views the "stillness" of Asian students as a problem of passive learners by theorizing a concept of "scholarly habitus." They point out that a productive stillness, such as quiet attention and concentration on learning tasks, is central to the formation of scholarly habitus, which consequently fosters students' academic performance. Both studies use Bourdieu's theoretical concepts to challenge the dominant Western and often pathologized perceptions of racialized minorities, such as "Black youth lack cultural capital" or "Chinese students are problematic learners because they are too quiet." This paper aims to expand Bourdieusian analysis in educational research from class to race by developing and elaborating on a concept of racialized habitus, which can be briefly defined as a racist social structure internalized by social agents, or a system of racialized social dispositions that consciously or unconsciously affect social agents' ways of thinking, being, and doing, particularly in their interactions with racialized minorities. For instance, some teachers might demonstrate a racialized habitus by having differential expectations of white students and Chinese students based on racial stereotypes (Cui, 2017), or some Canadian-born Chinese students may derogatively call their newcomer Chinese counterparts "FOB" (i.e., fresh off the boat) and intentionally avoid social contact with them in order to prove that they themselves are "real" Canadians (Cui, 2015). In this paper, I focus on how the model minority stereotype, in its three negative connotations, affects social agents by developing a racialized habitus in their interactions with Chinese Canadian youth.

\section{The study}

This article draws on interview data from a research project that examines identity construction among first- 
and second-generation Chinese Canadian youth in Alberta. According to Statistics Canada (2011), 20.6\% of the Canadian population is foreign born, and these immigrants mainly settle in four provinces: Ontario, British Columbia, Quebec, and Alberta. Among 644,100 foreign-born immigrants in Alberta, Chinese immigrants are the second-largest racialized group after South Asians. Recruitment flyers were distributed to several local Chinese community organizations, campuses of the University of Alberta and University of Calgary (e.g., on the bulletin board in the cafeteria, libraries, and student residence buildings), and local Chinese websites. My final sample used in this study included 35 Chinese Canadian youth in Edmonton and Calgary. Among them, there were 18 males and 17 females aged between 15 and 24, with an average age of 19. Of these, 20 participants had migrated with their parents to Canada after they were 6 years old (first generation), while 15 were either born in Canada or migrated before the age of 6 (second generation). Regarding their parents' place of origin, 24 participants indicated that their family came from mainland China, 10 from Hong Kong, and one from Taiwan. Their parents' occupations ranged from university professors, business people, engineers, and technicians, to bus drivers, restaurant cooks, housekeepers, and the unemployed. During the 1-1.5-hour interview, participants were asked to talk about the factors affecting their identity construction at school, within the family, and through their formative contact with Canadian mainstream media. The "Too Asian" article was published in Maclean's magazine in the later stage of my data collection, so only some of the participants were asked to read the article in advance and voice their opinions during the interview. Interviews were transcribed verbatim. Interview transcripts, memos, and codes were organized and managed through qualitative data analysis software, Atlas-Ti.

As a researcher, I was conscious of how my social positions as a non-native English speaker, a middle-class Asian female from mainland China, a former international student, and now a Canadian citizen affected the whole research design and process. This included, for example, the research topic I chose. The topic of model minority stereotype and racism first drew my attention when I came to study in a Canadian university as an international graduate student more than 15 years ago. This life or career transition significantly shifted my social status from a privileged faculty member in a top university in China to a subordinate position as a female racialized minority, or "visible minority" (in official discourse) in Canada. I suddenly found that how I perceived myself (e.g., who I am) was totally different from what local people thought of me due to the negative connotations associated with the model minority stereotype of Chinese students. This realization triggered my research interest in social justice, particularly exclusion and oppression based on race and ethnicity. The purpose of this study is to make the silenced voices of Chinese students heard, to bring the invisible to light, and to draw people's attention to the deeply rooted social problem of racism which is hidden under the rosy picture that Canada is a multicultural society with few race issues. Based on the interview data, three themes related to model minority stereotype were identified: academic achievers (who are viewed as foreign competitors and antisocial nerds), undesirable immigrants, and the obedient and weak. Each of these stereotypes is discussed below.

\section{Academic achievers: Foreign competitors and antisocial nerds}

The model minority stereotype depicts Asian students as academic achievers. This seemingly positive discourse often carries negative connotations, however, such as foreign competitors or antisocial nerds. For example, in the “Too Asian?" article published by Maclean's, the authors quote an Asian student: "At graduation a Canadian-i.e. 'white'-mother told me that I'm the reason her son didn't get a space in university and that all the immigrants in the country are taking up university spots" (Findlay \& Köhler, 2010, p. 78). Such biased belief that regards (Asian) immigrants and their descendants as foreign competitors who take up "our" limited resources is not only held by an individual white parent, but also by some educated teachers (Cui, 2017). One of my participants, Michael, mentioned an uncomfortable experience he had in his grade 10 biology class when his teacher criticized the increasing population of immigrants: 
With all the immigrants coming in ... the world will come to an end ... People here have started losing their jobs. Immigrants are having so many kids ... so we will run out of supplies. So, the end of the world.

The above examples reflect typical racist ways of thinking held by some Canadians who treat (Asian) immigrants and their descendants as forever outsiders whose achievements and progress are not celebrated as a part of Canadians but are narrow-mindedly interpreted as competition and a threat to "real" Canadians (Cui \& Kelly, 2013). Although Canada is internationally acclaimed as an immigrant country and a multicultural society, the historical anti-immigrant sentiments did not disappear with the past but have been discursively maintained and reproduced in contemporary fields (e.g., media and school) and internalized by some individuals as a racialized habitus. The racialized habitus displayed by the white parent and the teacher is characterized by a race-based and biased distinction between "us" and "them," which further frames their logic of reasoning that attributes "our disadvantage/failure" to "their advantage/success." Arguing against the assumption that immigrants are harmful to Canada and its economy, Peter Li (2003) writes that "on the contrary, most studies indicate that immigrants have contributed to Canada in a variety of ways, and the weight of evidence suggests that Canada has benefited from immigration" (p. 99). By scapegoating Asian students for the educational failure of some white students, such ways of thinking simplistically reduce the multifaceted issue of university access to the single factor of race. In response to "Too Asian?" Jason, a first-generation immigrant youth from Hong Kong, explained how he finally got accepted into university with limited knowledge of English.

Because I spent triple amount of time in studying, in looking through dictionary, until it got ripped. I spent triple amount of time learning a language that I am not even familiar with. And I got into university ... You know, they are denying your effort.

In addition to teachers, some students also develop a racialized habitus that treats Asian students with good academic performance as foreign competitors. For example, as the only Asian student in his school, Michael's academic achievements did not help him win peer respect and friendship; rather, they subjected him to discrimination and marginalization (Cui, 2015). As Michael revealed:

So the white kids, I don't think they've ever met an Asian person before in their life, so they are a bit nervous in a way, but also cautious in their attitude toward me. Also, at the same time, they are a bit discriminatory. Because just by appearance I look different from them, and also by academic achievement, I differ from them quite a bit too.

Here, Michael attributed the peer discrimination he suffered not just to his racialized body, but also to his academic achievement. In that specific school field, his academic capital was not highly valued but treated as a threat because he was seen as competing with white students for limited symbolic capital, such as good grades.

The academic achiever identity is often linked with another derogatory attribute-the antisocial nerd. For example, the "Too Asian" article justified its argument for limiting the acceptance of Asian students to Canadian universities on the grounds that Asian students are antisocial so their very presence on Canadian campuses ruins the traditional university life which is characterized by parties, sports, and alcohol. The authors blamed Asian students for creating ethnic claves and segregation.

Asian students work harder ... they tend to be strivers, high achievers and single-minded in their approach to university ... White students, by contrast, are more likely to choose universities and build their school lives around social interactions, athletics and self-actualization-and, yes, alcohol. When the two styles collide, the result is separation rather than integration. (Findlay \& Köhler, 2010, p. 78) 
Such a way of thinking essentializes cultural differences between "Asians" and "whites" (Cui \& Kelly, 2013). It denies the heterogeneous nature of Asian cultures. Even students of Chinese origin (e.g., those from mainland China, Hong Kong, Taiwan, etc.) do not share a common Chinese culture, given the completely different historical, social, cultural, political, and economic contexts of these regions. Working hard and having high educational aspirations have nothing to do with an essentialized Asian culture, but with a valued work ethic many parents cultivate in their children, regardless of their racial and ethnic backgrounds. Similarly, not all white students define their university life in terms of party, sports, and alcohol. In response to the "Too Asian?" article, Dong, a firstgeneration Chinese boy argued:

It's just racist. Um, I think Asian students do work hard, like the majority of the people I know, they work hard. But I also have Caucasian friends who also work really, really hard. And so I think it's a fair game, it doesn't matter if you're white or not white.

Moreover, working hard at school with less involvement in social activities such as sports, parties, and drinking should not be simplistically understood as a personal or cultural preference. Some first-generation immigrant youth, like Jason, have had to deal with many adaptation difficulties such as language barriers, so they may not have the same time, energy, resources, or even interest in university social life that some local Canadian students have, given the pressures of school work. Further, the dominant white peer group may not really want to include Asian students in those social activities due to the function of their racialized habitus. In other words, we cannot blame the victims for the exclusion they encounter. In this sense, working hard and engaging in fewer social activities should not be interpreted as single-minded or antisocial, under the assumption that it is only based on individual free choice; rather, it is a strategic tool that many immigrant students and racialized minorities have to employ in order to achieve educational and career success in the face of various structural constraints, adaptation difficulties, and inequalities (Cui \& Kelly, 2013; Guo, 2013).

It is important to note that at school, the antisocial nerd discourse serves to delegitimate and devalue the academic and cultural capital of Chinese students, which consequently denies their entrance into the social field of peer groups. So, for example, Sandra revealed that in order to be accepted by her classmates, she would "try not to read or study in front of people, or people will think I'm a nerd." That was why, during the interview, some participants tried to highlight various social activities and clubs they were involved in, to prove they were "normal" people, not antisocial nerds. Obviously, the model minority stereotype not only affects the development of racialized habitus among dominant white groups, but also the ways of thinking, especially the identity construction, of Chinese students. This is what Reay (2002) points out as the "psychic cost" that some working-class students paid when they tried to fit into the working-class peer group while at the same time manage to do well at school. In fact, rather than blaming individuals for their "cultural" or "behaviour" or "personality" problem, we need to look at the contributing structural constraints. More importantly, what does a real multicultural society mean? To what extent can we allow people to be themselves rather than measuring them against a Western/Canadian "norm"?

\section{People from China: The undesirable and the inferior}

Chinese students have also been treated as undesirable immigrants. As Wang (2008) argues, there is a "thin line of demarcation between model minority and yellow peril" (p. 31). It is important to realize that as the popular stereotype shifted from "yellow peril" to "model minority," the latter did not completely replace the former; rather, these two seemingly contradictory stereotypes harmoniously coexist like two sides of a coin, with one temporarily taking precedence over the other various times.

Historically, Chinese immigrant labourers were hired to build the Canadian Pacific Railway (CPR) when 
employers had difficulty finding local white labourers. Once the CPR work was completed, the Canadian government immediately instituted a Chinese head tax in 1885 and passed the Chinese Immigration Act in 1923, which completely barred Chinese immigrants from entering Canada. The systemic racism against Chinese people was justified in terms of cultural deficits; Chinese immigrants were denigrated as a group of undesirable and inassimilable "heathen Chinee" without "civilized habits and religious aspirations" (Royal Commission report, 1885, as cited by Anderson, 1991, p. 54). What remains hidden behind these cultural excuses are economic and political rationales for exclusion (Cui, 2017). Economically, Chinese labourers were used by European colonists to maintain a disposable, subservient labour force at marginal cost to meet the unpredictable labour supply and demand of the capitalist system (P. S. Li, 1998). Politically, during the critical transition period of Canada's nation building, the dominant group attempted to maintain a white settler society. Anti-Chinese sentiments and movements were manifested in almost all the major institutions of Canadian society. Schools were not an exception.

According to Timothy Stanley (2011), during the early decades of the $20^{\text {th }}$ century, Chinese children experienced segregation in almost all the government-controlled schools in British Columbia in the name of health and the moral threat they presumably posed to white students. For example. Chinese children were segregated into a special class, a segregated school, or a tent in a city park. The younger generations were indoctrinated with "white supremacist forms of knowledge" through official curriculum (Stanley, 2011, p. 96). For example, an elementary school textbook authorized for use in BC between 1911 and 1923 described the "White Race" as "the most active, enterprising, and intelligent race in the world" while "the Yellow Race" was characterized as "some of the most backward tribes of the world [who,] as a rule, are not progressive" (p. 108). By combining racial concepts with the authority of science, students learned "at the same time they learned how to write" (p. 112) that Chinese are aliens who have different characters and qualities than whites.

This is the historical field in which older generations of Canadians were educated and their racialized habitus against Chinese people evolved, which may have affected their and their descendants' perceptions of and actions toward Chinese people. As Bourdieu (1990) argues, "the habitus, a product of history, produces individual and collective practices-more history-in accordance with the schemes generated by history" (p. 54). My interview with one Chinese immigrant youth further demonstrates this point. Hua, a first-generation Chinese girl, recalled that her social studies teacher attributed the exclusion of Chinese immigrants in history to their undesirable consumption styles:

I remember my social studies teacher told us that many Chinese immigrants came to Canada to build the Canadian Pacific Railway; they got paid and then became very rich. But they didn't spend money. Many Caucasian labourers did not understand why the Chinese like to save and become rich rather than spend money. It did not make sense to them, so since then, they began to discriminate against Chinese immigrants. (Author's translation)

By blaming the victims for their exclusion in the name of their cultural deficit, Hua's teacher not only denied the economic exploitation and political oppression that Chinese labourers experienced in Canadian history, but also reproduced the yellow peril discourse that perceives Chinese people as uncivilized, undesirable, and inferior (Cui, 2017).

Similarly, Ping described what happened to her in a grade 6 social studies class when they read a chapter about China:

The textbook was written many decades ago. It doesn't have a real, good description of China; [it is] very terrible. So some students said, 'Oh, China looks so bad, the streets are very dirty, their currency is not valuable. Pollution is everywhere.' At that time, I told them, 'China does not look like that' because 
I am from China.

However, the social studies teacher did not give Ping an opportunity to discuss her lived experiences in China. Instead, she criticized China as an inferior country compared with Western democracy and civilization. Ping felt hurt and upset by her teacher's and classmates' ignorance, sense of superiority, and humiliation of her (Cui, 2017). Matt shared a similar experience in hanging out with his white friends.

In junior high, I had most of my friends were Caucasian again ... Sometimes they'd make jokes about foreigners that I didn't really appreciate too much ... [such as] we use chopsticks instead of forks ... I don't know they kind of viewed other cultures as slightly inferior to the Western ones ... they tried to impose their views on me, so yeah, they say, "Oh, Canada is much better than where I come from." For a short period of time, I did hate myself for being different than other people, but eventually I began to realize it's a stupid thing to think about because I mean I can't change that, so I just have to deal with what I have already.

As Edward Said (1978) said, “The Orient was Orientalized not only because it was discovered to be 'Oriental' in all those ways considered common place by an average nineteenth-century European, but also because it could be-that is, submitted to being-made Oriental" (p. 6). The above examples demonstrate how racialized habitus can be characterized as a distinction between the West and the rest, the civilized and uncivilized, the master and slave (Anderson, 1991). The distinction between the Orient and the Occident, according to Said (1978), was ideologically constructed by Europeans to justify colonialism and to maintain unequal cultural and moral power relations with non-Europeans. Nowadays such distinction continues to devalue the cultural capital (e.g., consumption/living style, knowledge of China) of Chinese people and at the same time reproduces the unequal power relations between the West and the rest. People from China continue to be viewed as undesirable and inferior from a Western lens, a key component central to social agents' racialized habitus toward model minorities.

For Bourdieu and Wacquant (1992), it is the knowledge of the field in which social agents evolve that allows us to grasp "the roots of their singularity, their points of view or position (in a field)" (p. 107, italics in original). Social agents' practices cannot be simply deduced either from the present condition of the field which may have provoked them or from the past condition which constructed their habitus; rather, their practices have to be understood as the interplay of these two states of the field. Compared with the present condition, the long period of the past seems to play a more important role in producing and framing social agents' practices, "because of which," Bourdieu (1990) said, "we have emerged in the form we have today" (p. 56). The racialized habitus exemplified above can be understood as a product of both the past and the present fields (Cui, 2017). The yellow peril discourse has been discursively reproduced across these fields, combined with the model minority stereotype, and has contributed to the development of a racialized habitus against Chinese people and other Asians. The social order of the field is still based on a racial hierarchy with the West on the top and the rest at the bottom.

\section{Being picked on: The obedient and the weak}

What is also problematic with the model minority stereotype is that it tends to represent Asian people as docile, quiet, timid, respectful to authorities, not complaining about overtime work and other unjust treatment, and not demanding more rights from governments or pay increase and promotion from employers (Li \& Wang, 2008). When such stereotyped assumptions are projected onto Chinese students at school, it places them in a disadvantaged position where they are seen as obedient and weak and thus easily picked on by peers and teachers. Michael reported that he was occasionally addressed with racial slurs such as "Chinaman" or "Chink" at school. Despite his good academic performance, Michael recalled being excluded from school projects: "Basically all the 
white kids got into groups and I was forced to be excluded from any of the groups ... eventually I got into a group and then they started piling all the work to me." Fang was also excluded from school projects as an immigrant teenage girl, but as she stated, it depended on which project. If it was a mathematics project, her classmates were willing to include her, because "she can do all the work." However, if it was an English project or physical education class, she would be left out by them. At those moments, she felt hurt and suffered low self-esteem. In addition to such peer marginalization and exclusion, several Chinese students shared their experiences of being verbally and physically bullied. Olivia noted:

There were always teasing from students. The low chances are like, Me Chinese Me no Dumb. I cannot remember what other part of the teasing was but that always bugs me. They do actions. It really, really bugs me because it made fun of Chinese people.

For Cathy, an immigrant girl with limited English proficiency, her junior high school experience was associated with some unpleasant memories of "being made fun of" by school peers.

C: They call me different last names like Cathy Yang, Cathy Bang and all these other names. There was this one time that this guy called me Cathy Electra.

I: Electra?

C: It's a porn star ... And they make fun of my height too because I am short.

When facing peer harassment, it is important to note that both Olivia and Cathy chose to remain silent. In their words, they "just ignore it." When asked why they didn't "do something," Olivia explained, "because the more you confront them about it, the more they are going to do it to you." For Cathy, the reason to endure peer bullying was because, compared with a Chinese boy who was also picked on in her school, "mine wasn't worse as his."

A sense of powerlessness in dealing with those difficult situations was not only experienced by quiet girls like Olivia and Cathy, but also by Ping, who once actively engaged in resistance. As discussed before, when Ping's teacher criticized China in a social studies class, and Ping's peers began to laugh at her for coming from such a backward country compared to the Western world, Ping felt humiliated and angry. She began to argue against such Eurocentric views by saying that China was not like what they imagined. However, her resistance exacerbated her previous weak peer relations due to her excellent academic performance compared with others, and she encountered a physical attack in a gym class where she was hit by dodge ball by some girls "accidently on purpose." In reflecting on her difficult time as a first-generation immigrant girl at school, Ping acknowledged that she was different from her Chinese friends who were quiet and obedient, so "other students won't pick on them," whereas she would "stand up for my values" and "fight back." However, her resistance triggered further peer harassment, including malicious gossip about her to the point that she could not endure it any more. Her situation became temporarily better until her parents sensed something was wrong and brought the issues to the attention of the school principal. Similarly, Megan also mentioned a hard time she experienced in her PE class where she was hit by the balls and marginalized by peers:

I had a hard time with it when I was in elementary school, but I think it just gave me a bad experience of it and it's mostly team-oriented sports and where things are getting thrown around where it's an issue. I've tried a lot to get better at individual sports. I run and I bicycle so I'm not really bad now, but I understand that there's a social circle around team sports and it's never been where l've wanted to be.

In the UK, in examining the racism that British Chinese pupils experienced, Louise Archer and Becky Francis (2005) found that the popular stereotype that Chinese students are quiet and passive exposed them to increased 
racism and bullying "as a result of being seen as weak by other pupils" (p. 394). This is partly because of the dominant gender discourse that constructs the ideal pupil as male, assertive, and confident, so the perceived passivity and quietness of Chinese students is seen as problematic. The intersection of masculinity and model minority discourse reinforced the racist way of thinking that sees Chinese students as feminine, soft, and thus easily picked on (Cui, 2015).

From a psychological perspective, Volk, Dane, and Marini (2014) redefine bullying as an imbalance of power between the bullies and the victims. The power could be conceptualized as physical, cognitive, and/or social. The cognitive power of bullies, such as their verbal fluency, may aid them in selecting and teasing a less articulate victim or persuading peers to engage in social exclusion. The social power refers to bullies' social status, such as their popularity, which may facilitate them in committing relationally aggressive acts (e.g., recruiting classmates to exclude a target peer). It is beyond the scope of this paper to comprehensively examine the topic of bullying. However, interdisciplinary evidence has linked school bullying with unequal power relations (Volk, Dane, \& Marini, 2014).

In the case of Chinese students, such unequal power relations between bullies and victims should not be simply understood in an individual way (e.g., individual power imbalance), but as relations between the dominant and subordinated groups. The bullying that Chinese students experience does not just happen in that specific moment and field but is deeply embedded in history as a collective racialized habitus. In the above examples, Michael, Olivia, Ping, and Megan were bullied not just by an individual "bad" student; rather, they were subject to a collective symbolic violence in which sometimes the whole class was engaged. When Michael was marginalized in a school project, for example, nobody stood up to challenge it. When Ping tried to voice her opinion about what China looks like, nobody wanted to listen to her, but they collectively joined in reproducing the Eurocentric dichotomy between the West and the rest. When Megan and Ping were hit by balls in the gym, nobody helped them. It seemed that everyone has "a feel for the game" that these actions are doable and go without saying (Bourdieu, 1994). As Bourdieu (1990) argues, racialized habitus as durable dispositions tends to ensure the active presence of past racist history. It is characterized as racist schemes of perception, thought, and action that tend to "guarantee the 'correctness' of practices and their constancy over time" (p. 54). This is not to say that social agents' racialized habitus is fixed. Instead, it is always evolving in relation to field, capital, and the social order of the field. In the above examples, it seemed that the rules of the game in the social field of those schools is still based on racial hierarchy with the white students on top and the racialized minorities at the bottom. The model minority stereotype and its associated unequal power relations between the dominant and subordinated groups places Chinese students in a disadvantaged position in terms of school bullying. Most importantly, the stereotype contributes to the development of racialized habitus among students in terms of who is considered inferior, weak, and powerless-in other words, who can be potential targets of bullying with little cost.

\section{Conclusion}

Chinese students are often labelled as a model minority, an ideologically and politically constructed identity that tends to highlight their academic achievements while leaving their struggles as racialized minorities unattended. This seemingly positive racial stereotype is in fact associated with various derogatory connotations. In this paper, I have drawn on both an article published in a mainstream Canadian magazine and on interview data with Chinese Canadian youth to discuss three negative connotations linked with the model minority stereotype and how they reflect and contribute to the evolvement of racialized habitus against Chinese students. Specifically, I argue that the academic achievements of Chinese students are not celebrated as part of Canadian achievements but interpreted as competition and a threat against "real" Canadians (e.g., the white ones). Chinese students' academic capital is 
devalued in some school fields and their cultural capital, exemplified as an ethic of hard work, is often denigrated as single-minded or lacking interest in social activities or social skills. Racialized habitus based on the model minority stereotype is also characteristic of a Eurocentric dichotomy between the West and the rest (e.g., the civilized vs. uncivilized). Such ways of thinking treat Chinese students and their cultural capital (e.g., knowledge about China, consumption styles) as a deficit: undesirable and inferior. Moreover, the model minority stereotype depicts Chinese students as quiet and obedient, thereby contributing to a kind of racialized habitus that perceives them as targets of peer bullying. These three negative connotations associated with the model minority stereotype serve to categorize Chinese students into a subordinate social status. Such categorization, according to Bourdieu (1984), is a process in which "correspondence between membership of a category" and "possession of a particular property" is built, so that "knowledge of a person's category strongly influences judgments of him" (p. 479). In other words, the model minority stereotype plays an important role in distinguishing Chinese students as Others, who are different from and inferior to "real" Canadians.

How is social order, such as racial hierarchy, reproduced in an educational field? According to Bourdieu and Wacquant (1992), the reproduction of racialized social structure could not be realized without the collaboration of social agents who have internalized "the imminent law of the structure" in the form of habitus (p. 140). Their habitus inclines them to perceive this social order as natural and normal. Therefore, with the function of habitus, they reproduce the social structure "in the very spontaneous movement of their existence," regardless of whether they are conscious of it or not (p. 139). To challenge racial hierarchy requires us not only to interrogate institutional and systemic racism (e.g., laws and policies) but also to critically reflect on how racism has been maintained and reproduced at the individual level as racialized habitus. More research is needed to explore how to change racialized habitus in order to provide an equal and fair society for racialized minorities in Canada. 


\section{References}

Anderson, K. J. (1991). Vancouver's Chinatown: Racial discourse in Canada, 1875-1980. Montreal \& Kingston: McGill-Queen's University Press.

Archer, L., \& Francis, B. (2005). Constructions of racism by British Chinese pupils and parents. Race Ethnicity and Education, 8(4), 387-407. https://doi.org/10.1080/13613320500323971

Assalone, A. E., \& Fann, A. (2017). Understanding the influence of model minority stereotypes on Asian American community college students. Community College Journal of Research and Practice, 41(7), 422-435. https://doi.org/10.1080/10668926.2016.119 5305

Ball, S. J., Davies, J., David, M., \& Reay, D. (2002). “Classification" and "judgement”: Social class and the "cognitive structures" of choice of higher education. British Journal of Sociology of Education, 23(1), 51-72. https://doi.org/10.1080/01425690120102854

Bourdieu, P. (1977). Outline of a theory of practice. Cambridge, UK: Cambridge University Press.

Bourdieu, P. (1984). Distinction: A social critique of the judgement of taste. Cambridge, MA: Harvard University Press.

Bourdieu, P. (1986). Forms of capital. In J. G. Richardson (Ed.), Handbook of theory and research for the sociology of education (pp. 241258). New York, NY: Greenwood Press.

Bourdieu, P. (1990). The logic of practice. Cambridge, UK: Polity Press.

Bourdieu, P. (1994). In other words: Essays towards a reflexive sociology. Cambridge, UK: Polity Press.

Bourdieu, P. (1998). On television and journalism. London, UK: Pluto.

Bourdieu, P., \& Wacquant, L. (1992). An invitation to reflexive sociology. Cambridge, UK: Polity Press.

Boyd, M. (2008). Variations in socioeconomic outcomes of second generation young adults. Canadian Diversity, 6(2), $20-24$.

Chang B. (2017). Asian Americans and education. In The Oxford research encyclopedia of education (pp. 1-39). Oxford, UK: Oxford University Press. https://doi.org/10.1093/acrefore/9780190264093.013.102

Chou, R., \& Feagin, J (2008). The myth of the model minority: Asian Americans facing racism. Boulder, CO: Paradigm.

Cui, D. (2015). Capital, distinction, and racialized habitus: Immigrant youth in the fields of Canadian schools. Journal of Youth Studies, 18(9), 1154-1169. https://doi.org/10.1080/13676261.2015.1020932

Cui, D. (2017). Teachers' racialised habitus in school knowledge construction: A Bourdieusian analysis of social inequality beyond class. British Journal of Sociology of Education, 38(8), 1152-1164. https://doi.org/10.1080/01425692.2016.1251303

Cui, D., \& Kelly, J. (2013). “Too Asian?” or the invisible citizen on the other side of the nation? The Journal of International Migration and Integration, 14(1), 157-174. https://doi.org/10.10072Fs12134-012-0235-7

Findlay, S., \& Köhler, N. (2010, November 22). Too Asia? Maclean's, 123(45), 76-81. Retrieved from http://www2.macleans.ca/2010/11/10/ too-asian/

Guo, S. (2013). Economic integration of recent Chinese immigrants in Canada's second-tier cities: The triple glass effect and immigrants' downward social mobility. Canadian Ethnic Studies, 45(3), 95-115. https://doi.org/10.1353/ces.2013.0047

Lareau, A., Evans, S. A., \& Yee, A. (2016). The rules of the game and the uncertain transmission of advantage: Middle-class parents' search for an urban kindergarten. Sociology of Education, 89 (4), 279-299. https://doi.org/10.1177/0038040716669568

Lee, J. (1998). Dynamics of ethnic identity: Three Asian American communities in Philadelphia. New York, NY: Garland.

Lee, R. G. (1999). Orientals: Asian Americans in popular culture. Philadelphia, PA: Temple University Press.

Lehmann, W. (2012). Working-class students, habitus, and the development of student roles: a Canadian case study. British Journal of 
Sociology of Education, 33(4), 527-546. https://doi.org/10.1080/01425692.2012.668834

Li, G. (2003). Literacy, culture, and politics of schooling: Counternarratives of a Chinese Canadian family. Anthropology \& Education Quarterly, 34(2), 182-204. https://doi.org/10.1525/aeq.2003.34.2.182

Li. G., \& Wang, L. (2008). Introduction: The old myth in a new time. In G. Li \& L. Wang (Eds.), Model minority myth revisited: An interdisciplinary approach to demystifying Asian American educational experiences (pp. 1-18). Charlotte, NC: Information Age.

Li, P. S. (1998). The Chinese in Canada (2 ${ }^{\text {nd }}$ ed.). Toronto, ON: Oxford University Press.

Li, P. S. (2003). Destination Canada: Immigration debates and issues. Don Mills, ON: Oxford University Press.

Marton, K. (2008). Habitus. In M. Grenfell (Ed.), Pierre Bourdieu: Key concepts (pp.49-65). Durham, NC: Acumen.

Museus, S. D. (2009). A critical analysis of the exclusion of Asian American from higher education research and discourse. In L. Zhan (Ed.), Asian American voices: Engaging, empowering, enabling (pp. 59-76). New York, NY: NLN Press.

Museus, S. D., \& Kiang, P. N. (2009). Deconstructing the model minority myth and how it contributes to the invisible minority reality in higher education research. New Directions for Institutional Research, (142), 5-15. https://doi.org/10.1002/ir.292

Peterson, W. (1966a). Success story: Japanese-American style. The New York Times, January 9.

Peterson, W. (1966b, December). Success story of one minority in the US. U.S. News and World Report.

Poon, O., Squire, D., Kodama, C., Byrd, A., Chan, J., Manzano, L., . . \& \& Bishundat, D. (2016). A critical review of the model minority myth in selected literature on Asian Americans and Pacific Islanders in higher education. Review of Educational Research, 86(2), 469-502. https://doi.org/10.3102/0034654315612205

Qin, D. B., Way, N., \& Mukherjee, P. (2008). The other side of the model minority story: The familial and peer challenges faced by Chinese American adolescents. Youth \& Society, 39(4), 480-506. https://doi.org/10.1177/0044118X08314233

Raby, R. (2004). "There's no racism at my school, it's just joking around": Ramifications for anti-racist education. Race, Ethnicity, and Education, 7(4), 367-383. https://doi.org/10.1080/1361332042000303388

Reay, D. (2002). Shaun's story: Troubling discourses of white working-class masculinities. Gender and Education, 14(3), 221-234. https:// doi.org/10.1080/0954025022000010695

Reay, D. (2004). "It's all becoming a habitus": Beyond the habitual use of habitus in educational research. British Journal of Sociology of Education, 25(4), 431-444. https://doi.org/10.1080/0142569042000236934

Reitz, J. G., \& Banerjee, R. (2007). Racial inequality, social cohesion and policy issues in Canada. In K. Banting, T. J. Courchene, \& E. L. Seidle (Eds.), Belonging? Diversity, recognition, and shared citizenship in Canada (pp. 489-545). Montreal, QC: Institute for Research on Public Policy.

Reitz, J. G., Zhang, H., \& Hawkins, N. (2011). Comparisons of the success of racial minority immigrant offspring in the United States, Canada, and Australia. Social Science Research 40(4): 1051-1066. Retrieved from https://munkschool.utoronto.ca/ethnicstudies/ files/2013/02/Reitz-Zhang-Hawkins-Comparisons-of-2nd-gen-success-SSR-40-2011.pdf

Said, E. (1978). Orientalism. New York, NY: Vintage.

Stanley, T. (2011). Contesting white supremacy: School segregation, anti-racism, and the making of Chinese Canadians. Vancouver: UBC Press.

Statistics Canada. (2011). Immigration and ethnocultural diversity in Canada: National household survey, 2011 (Catalogue no. 99-010x2011001). Retrieved from http://www12.statcan.gc.ca/nhs-enm/2011/as-sa/99-010-x/99-010-x2011001-eng.cfm

Suzuki, B. H. (2002). Revisiting the model minority stereotype: Implications for student affairs practice and higher education. New Directions for Student Services, (97), 21-32. https://doi.org/10.1002/ss.36 
Takagi, D. Y. (1992). The retreat from race: Asian American admissions and racial politics. New Brunswick, NJ: Rutgers University Press.

Thomson, P. (2008). Field. In M. Grenfell (Ed.), Pierre Bourdieu: Key concepts (pp. 67-81) Durham, NC: Acumen.

Volk, A. A., Dane, A. V., \& Marini, Z. A. (2014). What is bullying? A theoretical redefinition. Developmental Review, 34(4), $327-343$. http://dx.doi.org/10.1016/j.dr.2014.09.001

Wallace, D. (2017). Reading "race" in Bourdieu? Examining Black cultural capital among Black Caribbean youth in south London. Sociology 58(3), 24-50. https://doi.org/10.1177/0038038516643478

Wang, L. L. (2008). Myths and realities of Asian American success: Reassessing and redefining the "model minority" stereotype. In G. Li \& L. Wang (Eds.), Model minority myth revisited: An interdisciplinary approach to demystifying Asian American educational experiences (pp. 21-42). Charlotte, NC: Information Age.

Watkins, M., \& Noble, G. (2013). Disposed to learn: Schooling, ethnicity and the scholarly habitus. London, UK: Bloomsbury.

Wing, J. (2007). Beyond Black and white: The model minority myth and the invisibility of Asian American students. Urban Review, 39(4), 455-487. http://dx.doi.org/10.1007/s11256-007-0058-6

Yu, T. (2006). Challenging the politics of the "model minority" stereotype: A case for educational equality. Equity \& Excellence in Education, 39(4), 325-333. http://dx.doi.org/10.1080/10665680600932333

Zhang, Q. (2010). Asian Americans beyond the model minority stereotype: The nerdy and the left out. Journal of International \& Intercultural Communication, 3(1), 20-37. https://doi.org/10.1080/17513050903428109

\section{(Endnotes)}

